\title{
How Social Connections to Local CBNRM Institutions Shape Interaction: A Mixed Methods Case from Namibia
}

\author{
Julie Snorek ${ }^{1}$, Thomas Kraft ${ }^{2}$, Vignesh Chockalingam ${ }^{1}$, Alyssa Gao ${ }^{1} \&$ Meghna Ray $^{1}$ \\ ${ }^{1}$ Environmental Studies Department, Dartmouth College, Hanover, NH, USA \\ 2 Department of Anthropology, University of California Santa Barbara, CA, USA \\ Correspondence: Julie Snorek, Department of Environmental Studies, Dartmouth College, Hanover, NH, 03755 , \\ USA. Tel: 1-603-892-3496. E-mail: juliesnorek@gmail.com
}

Received: August 10, 2020

doi:10.5539/jsd.v13n6p26

\author{
Accepted: September 15, 2020 \\ Online Published: October 12, 2020 \\ URL: https://doi.org/10.5539/jsd.v13n6p26
}

\begin{abstract}
Strong social connections between communities and institutions are essential to effective community-based natural resource management. Connectivity and willingness to engage with actors across scales are related to one's perceptions of institutions managing natural resources. To better understand how individuals' perceptions are related to connections between communities and institutions, and how these promote or inhibit interaction across scales, we carried out a mixed methods case study on the multiple actors living and working in the Namib Naukluft National Park in Namibia. We took a descriptive approach to the social network analysis and identified distinct subgroups as well as boundary actors for the community-institutional network. Thereafter, we regressed interview data on connections, perceptions, and willingness to reach out to institutions to understand more about network dynamics. Finally, we performed a qualitative analysis of interview data, to further highlight why community individuals were connected to institutional members. Positive perceptions are associated with greater connectivity for two out of three institutions. Better quality connections between community members and institutions was equated with a greater willingness (of community members) to reach out to an institutional member in only one out of three cases. As in other studies, willingness to reach out may be more strongly correlated to intergroup actor dynamics, as shown by subgrouping in the social network analysis, than one's perceptions alone. This research highlights that direct interactions between community members and local institutions has the potential to support collaboration in the context of community-based natural resource management.
\end{abstract}

Keywords: social network analysis, community-based natural resource management, local institutions, Topnaar, Namib Naukluft National Park, Namibia

\section{Introduction}

Governance of natural resource regimes is shifting from central governments to local institutional actors (Nemarundwe 2003). In some cases, top-down approaches with command-and-control policies have been shown to be ineffective in managing shared resources (Sanginga et al. 2010; Vincent 2007; Olsson et al. 2006; Lebel et al. 2006; Dietz et al. 2003; Ostrom 1999). Governments in southern Africa have been particularly active in decentralizing natural resource management to communities and local institutions (Botelle \& Kowalski 1995; Mosimane \& Silva 2015; Gargallo 2020). In this case, local institutions are those situated within the natural resource regimes (such as a protected area) and serve to formalize rule making, develop social norms and shape how individuals and organizations act (Berman, Quinn \& Paavola 2012). Local institutions facilitate social learning and the involvement of local actors (Dietz et al. 2003; Olsson et al. 2006; Gupta et al. 2010; Chaffin et al. 2014). Long-term co-management of natural resources by communities and institutions depends upon coordinated efforts and a willingness for multiple actors to work together (Lebel et al. 2006; Fabricius et al 2007; Ostrom 2007; Sanginga 2010; Cox et al. 2010; Sjostead 2015). Social networks help to facilitate these coordinated approaches in community-based natural resource management (CBNRM), especially in areas where marginalization of local actors is prevalent (Bigdon 2006).

It has been shown that social connections have the potential to facilitate information exchange, foster commitment to common rules, and increase willingness to engage in monitoring, sanctioning, and conflict resolution in the context of CBNRM (Olsson \& Folke 2004; Pahl-Wostl 2009; Gupta et al. 2010, Bodin \& Crona 2009; Berman, Quinn \& Paavola 2012). Strong intergroup dynamics, characterized by one's social connections and a shared set 
of values and perceptions, are also an important factor when considering how to establish co-management of natural resources (Lauber 2008; Crona \& Bodin 2006; Bodin \& Crona 2009; Sanginga et al. 2010; Granovetter 1973). Yet social psychologists find that normative perspectives and biases, as well as homophily and physical or social distancing (McPherson et al. 2001, Erikson 1988), influence an individual's perspectives of and willingness to engage with those outside their group, such as institutional actors. Thus, the facilitation of exchanges, social learning, and commitment to common rules depend on social connections that create pathways for engagement (Cooley 1998, Festinger et al. 1950, Homans 1950, Kadushin 1966, Bodin \& Crona 2006). Given the marginalized status of many local communities engaged in CBNRM, bridging social connections between central and marginal sub-groups is particularly important for promoting coordinated approaches to CBNRM (Sanginga et al 2010; Bodin \& Crona 2006; Crona \& Bodin 2009; Lauber 2008).

\subsection{Case Study and Hypotheses}

We engaged in a mixed methods case study approach to assess, from the vantage point of community members, the community-to-institution linkages of social networks and their impact on community members' perceptions of the institutions working in the Namib Naukluft National Park (NNNP), Namibia. The community in this case includes the indigenous \#Aonin or Topnaar people, who have lived for centuries as pastoralists in the Namib Desert along the !Kuiseb river, an area which has been a protected area for the approximately 100 years. Their residence in a national park along with the local social and ecological conditions introduces multiple constraints on livelihoods - fodder shortages, human wildlife conflict, few economic opportunities, minimal social infrastructure, and inadequate access to information and transportation. Some of the institutions engaging with CBNRM in the park have been identified as: 1) Gobabeb Namib Research Institute (GBB) - an international research facility established in 1962 that studies and monitors the fragile arid ecosystems of the Namib desert from its base, embedded in the indigenous cultural landscape of the Topnaar pastoralists; 2) the Ministry of Environment and Tourism (MET) - a government body charged with protecting the biodiversity of Namibia's parks (including NNNP) while supporting co-benefits to rural communities through infrastructure development, employment creation, and income; 3) the Ministry of Agriculture, Water and Forestry (MAWF) - a government body promoting the efficient and sustainable socio-economic development of the rural sphere for a prosperous Namibia, including gardening and livestock rearing. These institutions and community members are important actors in fulfilling CBNRM goals in the park.

To understand more about community members' social connections, perceptions of institutions, and engagement with institutions, we carried out a case study of community-institutional relationships in the NNNP. Using social network analysis tools, we demonstrated visually the connections within the NNNP network. Then, to understand the community members themselves in relation to our line of inquiry, we hypothesized that homophily in relation to age and education as well as one's social or physical distance (McPherson et al. 2001) affects connectivity between community members and institutions (H1). Thereafter, we hypothesized that a community member's connectivity to individuals at institutions, characterized by the quality and quantity of the connections or ties, affects an individual's perceptions of that institution, wherein individuals who are more connected to institutions have more positive perceptions than less directly connected actors (H2). Finally, we hypothesized that community members who have greater connections to and positive perceptions of an institution will be more willing to reach out to or engage with institutions, which is necessary to foster a willingness to engage in adaptive co-management (H3) This evidence is further understood through qualitative analysis.

\section{Method}

\subsection{Research Area and Sample}

The Kuiseb River Valley area of the Namib Naukluft National Park (NNNP) is a geographically well-contained community-institution network formed by the Topnaar Community and the Traditional Authority (TTA) representing the community and Gobabeb Namib Research Institute (GBB), Ministry of Agriculture, Water, and Forestry (MAWF), and the Ministry of Environment and Tourism (MET) - representing the institutions serving in the NNNP (Figure 1) (Note 1). The TTA serves as the main liaison between communities and institutions and seeks to uphold the traditions of the Topnaar people. MAWF has one extension agent, also a member of the Topnaar community, embedded in the community of Utuceb, who is charged with informing and supporting agricultural development for the population. The MET has rangers patrolling the Park, but not living directly in the Topnaar communities. These actors interact in the context of community development and CBNRM initiatives.

We held an initial focus group discussion with community members attending a livestock workshop at GBB in October 2018. From this, we derived a survey aimed to understand how communities characterize their connections and engagement with and perceptions of institutions. Interviewees were subdivided into three categories: 1) 
Topnaar community members ( $\mathrm{N}=23), 2)$ GBB management, researchers, and staff $(\mathrm{N}=9), 3)$ Members of the Topnaar traditional authority $(\mathrm{N}=2)$. Based on an estimated total of 250 people living in the Park (Botelle \& McPherson 1995), we surveyed $12 \%$ of the local Topnaar population and $14 \%$ of the total population (including GBB) of people living in NNNP (Table 1).

Table 1. Overview of interviews conducted

\begin{tabular}{lcrc}
\hline Category & Interviewee Type & $\#$ \\
\hline Topnaar & Topnaar community members & 23 \\
Respective Villages (\# of & Aramstraat (7) & Swartbank (5) & \\
interviewees) & Goatanab (1) & Klipneus (1) \\
& Ururas (1) & Soutriver (2) \\
& Utuseb (4) & Natab (2) & \\
& Topnaar Traditional Authority & 2 \\
\hline Gobabeb Namib Research & GBB managers, researchers, and staff & & 9 \\
Institute & & TOTAL 34 \\
\hline
\end{tabular}

\subsection{Sampling Procedures}

Most Topnaar community members know each other and have strong inter-group connections. With the assistance of two Topnaar interpreters who speak Khoekhoe (Khoisan language of the Topnaar), we visited respondents in their homes, using a snowball sampling method. Informed consent process was obtained before each interview, and respondents were free to decline our interviews. We interviewed householders along an 80-km stretch of the Kuiseb River Valley in the villages from Ururas to Natab (Figure 1). These were diversified by sex $(43.5 \%$ women, $56.5 \%$ men), age ( $45 \%$ were $<40$ years old and $55 \%$ were $40+$ years old), education ( $60 \%$ had $0-9$ years education, $40 \%$ had $10+$ years education), residence location, and occupation. In some villages, there were only three to four inhabited households (e.g. Natab).

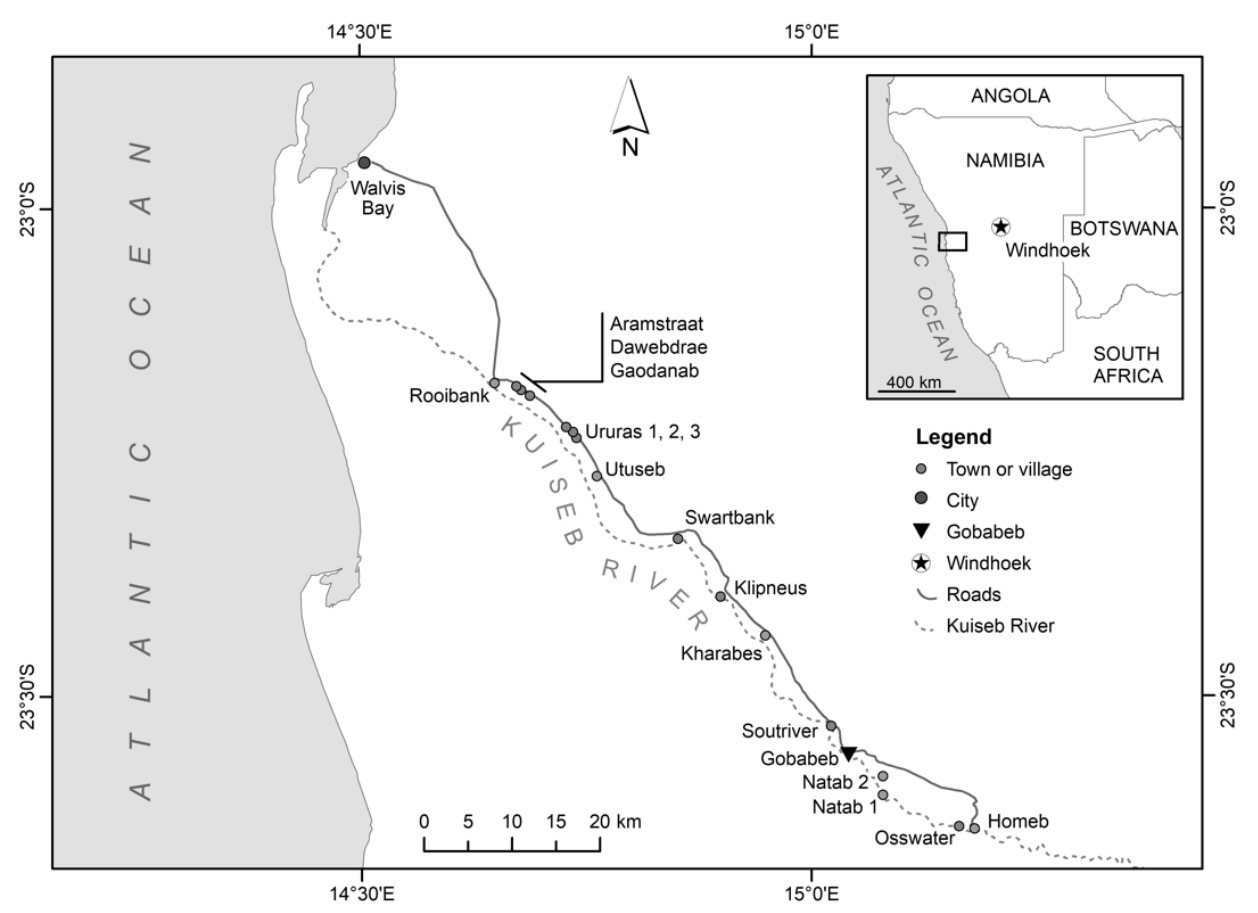

Figure 1. Map of Kuiseb River Valley and Topnaar communities and institutions (courtesy J.W. Chipman, Dartmouth College) 
To better understand community members' connectivity to institutions, we asked questions related to: 1) the number and types of community member-institutional connections; 2) the quality of relationships; 3 ) challenges to relationships with institutions; 4) prior experiences working with institutions; and 5) recommended areas of improvement for relationship with institutions. In addition to community interviews, we interviewed members of GBB (management, researchers, and the staff or maintenance team/workers) to understand generally how GBB as an institution perceives and engages with Topnaar communities. We also interviewed two members of the TTA in order to understand the role of the TTA in facilitating community-institution relations.

\subsection{Data Analysis}

\subsubsection{Developing Variables}

Qualitative interview data was categorized into quantitative variables representing the quality of individual community member connectivity, their perceptions, and their willingness to interact with three institutions - GBB, MAWF, and MET. Quantitative variables were used in both linear models and social network analysis to construct social network topography.

Connectivity. The 5-point connectivity variable (Q) was assessed using a Likert scale quality score that is based upon subjective evaluation of answers to questions about the type of communication, frequency, and nature of individual's relationships to a specific institution and its members. To assess the strength of each connection, we assigned a connectivity quality score ranging from zero to five - zero indicating a weak or non-existent connectivity and five indicating strong connectivity, based directly on responses to survey questions (Appendix 1).

Perception. The five-point perception variable $(\mathrm{P})$ uses the ratio of positive to negative opinions expressed during the interview to assess respondents' perceptions of an institution. If a respondent stated any three positive aspects of an institution and one negative statement in responding to questions relating to their perceptions about an institution, the ratio would be 3:1, resulting in a perception score of "okay" or a "balance of positive to negative opinions." If a respondent stated only negative perceptions, then this was evaluated as null, not as a negative score (Appendix 2).

Willingness to Engage Indicator. Using the survey responses to the question, "if you had a problem, would you reach out to X institution?", we developed a binary indicator $(1=y e s, 0=$ no) to reflect a respondent's willingness to engage or reach out to an institution for help with a problem.

\subsubsection{Social Network Analysis}

Community members were asked who they know and with whom they interact for the four institutions governing the NNNP, to illustrate the connectivity and give more insight into subgroups and boundary actors in the network. While we did not do a rigorous analysis of the social network due to limitations on the data collection, we include this analysis as a visualization to illustrate the topography of the social network, identify potential boundary actors in the network, and highlight actors' degree and betweenness centrality.

Within the social network, nodes represent individuals interviewed or referred to by an interviewee. Links between the nodes are not directed. Undirected links are weighted by the connectivity variable (Appendix 1). Using R (v3.2.0), we analyzed for degree (the extent to which a node connects to all other nodes in a social network) and betweenness centrality (how other actors mediate relations between other unconnected nodes or groups of nodes) of all nodes to understand the key actors that serve as bridges and brokers of information (Freeman 1977; Wey et al. 2008; Knoke and Yang 2008). For node $i$, the degree $\mathrm{C}_{\mathrm{D}}\left(\mathrm{N}_{\mathrm{i}}\right)$ is the sum of $i$ 's direct ties to the g-1 other actors (1).

$$
C_{D}\left(N_{i}\right)=\sum_{j=1}^{g} x_{i j}(i \neq j)
$$

To measure betweenness centrality, $g_{j k}$ is the number of geodesic paths (the shortest distance between two nodes) between $j$ and $k$ that contain the node $i$. Then, by dividing $g_{j k}\left(N_{i}\right)$ by $g_{j k}$ measures measures the number of geodesic paths connected to $j$ and $k$ in which node $i$ is involved (Knoke and Yang 2008). All the dyads (groups of nodes) not including node $i$ measures the extent to which $i$ sits on other nodes' geodesic paths (2).

$$
C_{B}\left(N_{i}\right)=\sum_{j<k} \frac{g_{j k}\left(N_{1}\right)}{g_{j k}}
$$

\subsubsection{Statistical Analysis}

We used OLS regression in Stata to evaluate the relationships between the community variables connectivity quality, perceptions, and willingness to interact with institutions. These assess linear relationships between community members' homophily and social distance and connectivity (H1), their connectivity and their 
perceptions (H2), and finally, their connectivity, perceptions and willingness to reach out to institutions (H3). Models included coefficients for age and years of education (H1, H2, and H3) as well as for sex and distance (for $\mathrm{H} 1$ only) relating to the relevant institution in order to isolate the relationship between connectivity, perceptions, and interaction and to analyze bias of demographic and structural factors.

H1: Homophily and Social Distance Hypothesis. Given that individuals with similar attributes often share similar attitudes (Kadushin 1966), we evaluated the impact of age, sex, education level, and geographical distance (independent variables) of community members from individuals embedded in institutions on their connectivity and perceptions (dependent variables). We considered the demographic and structural factors (Age = A; Sex $=S$; Education $=\mathrm{E}$, Distance $=\mathrm{D}$ ) that affect connectivity and are relevant when considering barriers to communication and integration of subgroups in the social network.

$$
\begin{gathered}
\text { Connectivity }=B_{0}+B_{1} A+B_{2} S+B_{3} E+B_{4} D+\epsilon_{0} \\
\text { Perception }=B_{0}+B_{1} A+B_{2} S+B_{3} E+B_{4} D+\epsilon_{0}
\end{gathered}
$$

H1a. Younger individuals under the age of 40 are more connected to (1) and have better perceptions of (2) institutions than those 40 and older $(+)$

H1b. Males are more connected to (1) and have better perceptions of (2) institutions than females $(+)$

H1c. Those with a level of education greater than 9 or more years, are more connected to (1) and have better perceptions of (2) institutions than less educated individuals $(+)$

H1d. Individuals living in communities that are closer to institutions, categorized as living less than $30 \mathrm{~km}$ from an institution, are more connected to (1) and have better perceptions of (2) institutions than are individuals living in communities further away from institutions. $(+)$

H2: Connectivity and Perception Hypotheses. We evaluated the effect of an individual's connectivity to an institution, in terms of quality $(\mathrm{Q})$ of an individual's connections to that institution, on the individual's perception $(\mathrm{P})$ of that institution. The error term is $\mathrm{u}_{0}$. We use connectivity quality which is a composite of both quantity/quality, both of which are inherently correlated, given the differential number of representatives of each institution.

H2. We expect that the higher the quality of an individual's connections to an institution, the better are his or her perceptions of that institutional actor $(+)$

$$
\text { Perceptions }=B_{0}+B_{1} Q+\epsilon_{0}
$$

H3: Willingness to Engage Hypothesis. We evaluated the effect of an individual's perceptions of and connectivity to an institution on their willingness to seek out that institution. Additionally, to examine whether connectivity has a greater impact on willingness to engage with institutions for which an individual has a positive perception, we include an interaction term $\left(\mathrm{B}_{3}\right)$ between connectivity and perception.

H3a. The better a community member's perceptions of an institution, the more willing he/she is to engage with that institution $(+)$

H3b. The more connected a community member is to an institution, the more willing he/she is to engage with that institution $(+)$

H3c. The better an individual's perception of an institution, the greater will be the impact of additional connectivity on their willingness to engage with that institution $(+)$

$$
\begin{gathered}
\text { Willingness }=B_{0}+B_{1} P+\epsilon_{0} \\
\text { Willingness }=B_{0}+B_{1} Q+\epsilon_{0} \\
\text { Willingness }=B_{0}+B_{1} Q+B_{2} * P+B_{3} * Q P+\epsilon_{0}
\end{gathered}
$$

\subsection{Qualitative Analysis}

Interview responses were analyzed through a deductive process using an iterative process of coding and categorizing statements made by respondents in Excel. Data was coded from field notes based on three categories of responses about community perceptions of institutions: 1) forms of support, 2) sources of dissatisfaction, and 3 ) areas recommended to improve. Interviews with members of institutions were categorized based on perceptions of 1) sources of dissatisfaction and 2) recommendations to improve.

\section{Results}

\subsection{Social Network Analysis}

The social network analysis illustrates the groupings and boundary actors in the network There are relatively few 
connections in the NNNP across community and institutional actor groups. The topology of the social network highlights the existence of distinct subgroups, indicated by the separate clustering of different nodes via dense connections (Figure 2). These subgroups include the TTA (purple nodes in Figure 2), Topnaar Community (red nodes) including GBB Topnaar staff (yellow nodes with GS\# codes), and GBB management and researchers (all other yellow nodes). Some key nodes serve to connect different clusters in the topology. For example, the Topnaar staff of GBB bridge the Topnaar community with the greater GBB staff, while the Topnaar Chief bridges the TTA with the Topnaar community and the GBB management.

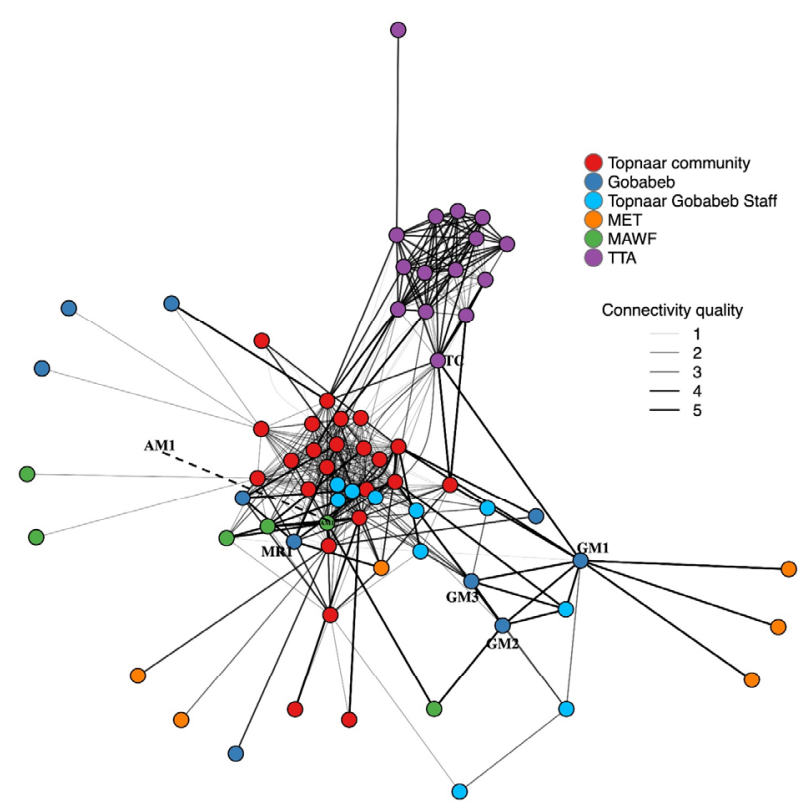

Figure 2. Social network topology of communities and institutions

Purple nodes $=$ TTA, red $=$ Topnaar community members, orange $=$ MET employees, green $=$ MAWF employees, dark blue $=$ GBB directors and researchers, and light blue $=$ GBB Topnaar staff. An undirected edge connects each node; the weight of the edge - how thick the line is - corresponds to the quality of the connection and is based on the connectivity quality score. The network diagram layout is weighted by connectivity quality and uses Fruchterman-Reingold force-directed algorithm available in R.

The TTA and the Topnaar community represent two distinct subgroups in the network, connected mainly by the late Topnaar chief. Boundary actors serve to connect subgroups in Figure 2 except for the subgroups for MAWF and MET, which are not separate clusters. Many of the community members are connected to GBB through the Topnaar GBB staff members (light blue). In turn, several MAWF individuals are closely linked to the community network, related to their strong presence living in the region and the fact that one is also a Topnaar. GBB managers, concurrently, are found embedded in the Topnaar community subgroup. One MET representative is well connected to the central subgroup but sits more at the periphery. 
Table 2. Centrality of key actors in the Kuiseb valley social network

\begin{tabular}{lll}
\hline & Degree & Betweenness Centrality \\
\hline GBB Manager - GM1 & 22 & 402.43 \\
Topnaar Chief - TC & 22 & 246.45 \\
GBB Manager - GM3 & 21 & 114.30 \\
GBB Manager - GM2 & 16 & 63.42 \\
MAWF Extension Officer - AM1 & 22 & 57.02 \\
MET Ranger - MR1 & 12 & 5.33 \\
\hline
\end{tabular}

The Topnaar Chief, GBB management (GM1), and MAWF Extension Officer (AM1) all have the highest degree (22), or quantity of ties to other nodes (Table 2). In the cases of the three GBB employees (GM1, GM2, and GM3), this is in part due to subgroup (the GBB workplace) connectivity amongst researchers and staff. Similarly, AM1 is also a Topnaar and thus possesses a high degree from ties to the Topnaar community. Betweenness centrality demonstrates the large influence of GM1 on multiple actors across the network as well as between subgroups. GM1, TC, GM3, and GM2 all have the largest betweenness centrality, which accords with their positioning closer to the center of the network (Table 2, Figure 2) and their role as a connection or boundary actor between their subgroups and others.

\subsection{Statistical Analysis}

Community members have on average higher numbers of connections with GBB (4.68), but the highest quality of connectivity to MAWF (2.80). Community members are also most willing to reach out to the MAWF, with $75 \%$ reporting they would be willing. In comparison, GBB has the lowest percentage of community members willing to reach out at $43 \%$.

Table 3. Summary of Topnaar community members' connectivity, perception, and willingness to engage indicators

\begin{tabular}{|c|c|c|c|}
\hline Relationship & Community Link Indicator & Average & Standard Deviation \\
\hline \multirow{3}{*}{ Community to GBB } & Connectivity Quality Score (1-5) & 2.53 & 1.68 \\
\hline & Perception Score (1-5) & 2.85 & 1.66 \\
\hline & Willing to Engage (\%) & 43 & 11 \\
\hline \multirow{3}{*}{ Community to MAWF } & Connectivity Quality Score (1-5) & 2.80 & 1.40 \\
\hline & Perception Score (1-5) & 3.30 & 1.17 \\
\hline & Willingness to Engage (\%) & 75 & 11 \\
\hline \multirow{3}{*}{ Community to MET } & Connectivity Quality Score (1-5) & 2.40 & 1.70 \\
\hline & Perception Score (1-5) & 2.32 & 1.67 \\
\hline & Willing to Engage (\%) & 61 & 11 \\
\hline
\end{tabular}




\subsubsection{Homophily and Physical Distance}

We find that the majority of demographic factors do not have a significant relationship with individuals' connectivity to or perceptions of institutions (Appendix 3). Education was positively correlated with connectivity in the isolated case of GBB. Youth do not have greater connectivity to or better perceptions of institutions than elders. Men do not have greater connectivity than women. Individuals with more formal education have no greater connectivity or perceptions than individuals with less formal education. Finally, physical distance - living close to as opposed to far away from an institution- is not associated with a community member's connectivity to or perception of an institution.

\subsubsection{Connectivity and Perceptions}

As shown in Figure 3 (see also Appendix 4), increased connectivity quality scores are significantly associated with more positive perceptions of GBB and MAWF (Models $2 \& 3$ in Appendix 4) but are unrelated to perceptions of the MET (Model 1). Community-MET relationship for connectivity quality and perception is insignificant (-0.126; $\mathrm{p}=0.249$ ). These findings support $\mathrm{H} 2$, suggesting that connectivity quality is positively and significantly associated with perceptions of institutions in the cases of Gobabeb and the MAWF, but not in the case of the MET.
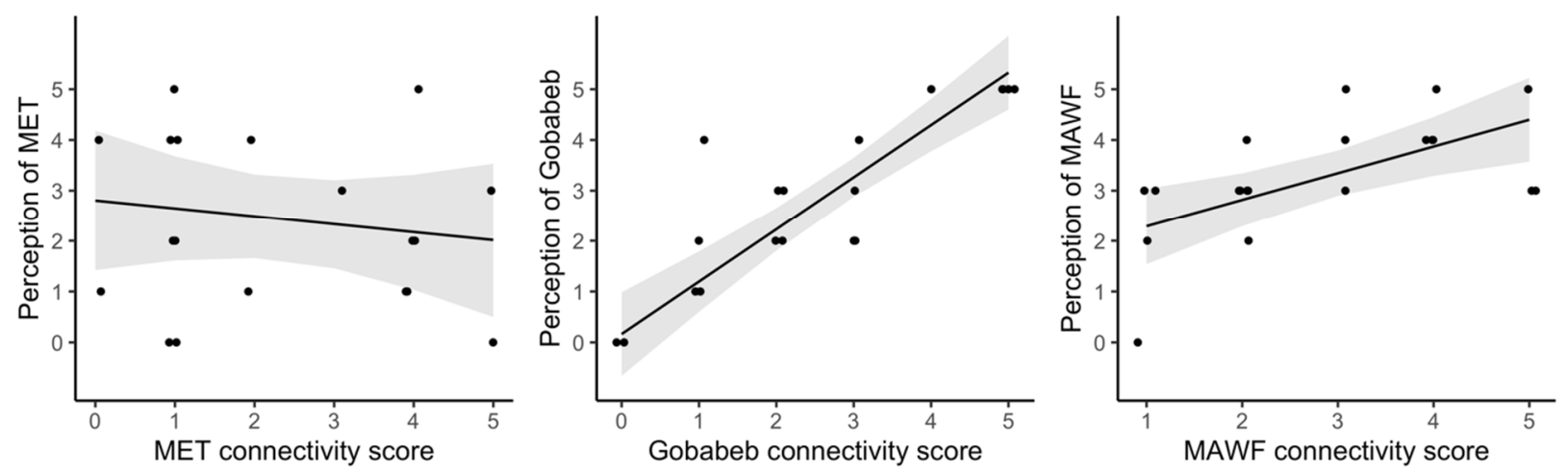

Figure 3. Perceptions of institutions as a function of connectivity score (Appendix 4). Each point represents a single individual. Regression lines (shaded 95\% confidence intervals) represent fits from models 1, 2, and 3 in Appendix 4. Points are jittered slightly on the horizontal axis for visualization

\subsubsection{Willingness to Engage}

Regressions in Figure 4 evaluate the relationship between community members' willingness to engage with an institution and their connectivity to that institution (H3a), their perception of that institution $(\mathrm{H} 3 \mathrm{~b})$, or the interaction of connectivity and perception together $(\mathrm{H} 3 \mathrm{c})$. Connectivity is associated with willingness to reach out to an institution in the cases of GBB and MAWF (Figure 4, Appendix 5). However, as before, this relationship is insignificant with regard to the MET $(0.012 ; \mathrm{p}=0.843)$. H3a is thus supported with regard to community member's willingness to reach out to GBB and MAWF, but not with respect to their willingness to reach out to the MET. Perception (H3b) is significantly associated with individuals' willingness to reach out to GBB, but not to either of the government ministries (Figure 4). We thus find only marginal support for H3b, that better perceptions are associated with more willingness to reach out to an institution. Finally, we do not find support for H3c. Across models in Figure 4, the interaction between connectivity and perception is not significant, due in part to collinearity, suggesting that the combined influence of these factors does not have a stronger association with the willingness to reach out to an institution (Appendix 5). 

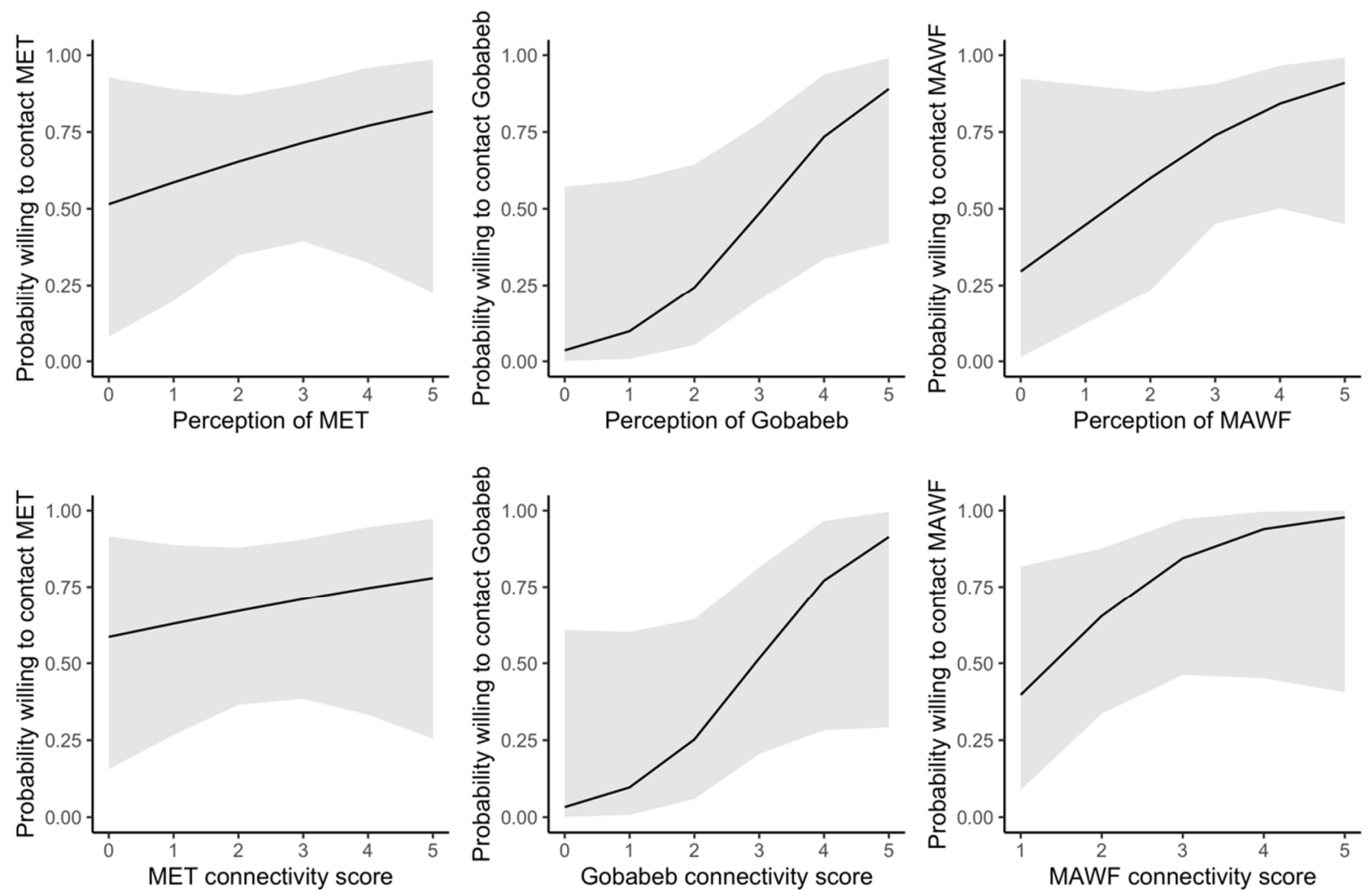

Figure 4. Predicted probability of willingness to contact institutions as a function of perception (top row) or connectivity score (bottom row) (Appendix 5). Fitted probabilities are derived from generalized linear models

with a binomial error distribution and logit link function holding all covariates at their mean values, and correspond to models 1, 2, 4, 5, 7, and 8 in Appendix 5. Shaded regions represent 95\% confidence intervals

\subsection{Qualitative Analysis}

\subsubsection{Perceptions of Institutions}

Community members expressed both positive and negative perceptions of each of the assessed institutions, highlighting forms of material and immaterial support, sources of dissatisfaction, and recommendations for improvement (Table 4). Positive comments centered around tangible (e.g. workshops) and intangible (e.g. availability) benefits. For example, one Topnaar community member attended a GBB sewing training that, "changed [her] life" (C5). Another community member praised the MAWF for providing workshops on livestock health and trainings for immunization injections. 
Table 4. Perceptions of institutions as stated by communities

\begin{tabular}{llll}
\hline & Perceptions of Gobabeb & Perceptions of MET & Perceptions of MAWF \\
\hline \multirow{4}{*}{ Forms of } & Employment (1) & & \\
Support & Trainings (6) & Workshops (2) & Workshops (2) \\
& Education* (8) & Predators removed (9) & Livestock health advice (5) \\
& Transport (3) & Protect wildlife (3) & Availability*** (6) \\
& Livelihood support (4) & Provide meat (1) & Gardening advice (1) \\
& Applied Research** (5) & & \\
\hline \multirow{5}{*}{ Sources of } & Don't provide transport (2) & & \\
Dissatisfaction & Few development actions & Human-wildlife conflict (8) & \\
& (2) & Park regulations (6) & Slow/lack of response (3) \\
& Don't engage community & Lack of !nara protection (2) & \\
& (2) & & \\
\hline
\end{tabular}

More education/trainings

(9)

Recommend-
ations for
improvement

More employment (6)

Engage the community (5)

Provide transport (5)

Share information (7)

Advocate for development

(4)
More employment (1)

More workshops (3)

Better extension svc. (2)

More predator removal (4)

Compensation for predator

attacks on livestock (6)
Share information (2)

Visit communities more

often (6)

More trainings (3)

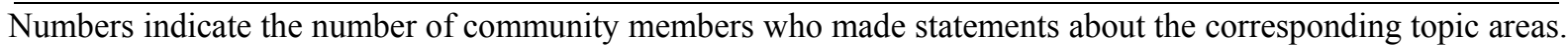
*Education refers to GBB's grade seven program and communicating research findings. **Applied research refers to research on Topnaar livelihoods. ${ }^{* * *}$ Availability refers to the ease to which one might reach these actors.

Community-institutional connectivity translates into positive interactions due in part to shared subgroup characteristics, such as culture, location or language (Figure 2). The MAWF representative (AM1) who is a 'member of the Topnaar family' is perceived as helpful for sharing relevant livelihood information. One Topnaar community member expressed that the local MAWF office is highly accessible, stating that he could contact these individuals, "any time night or day hours" (C7). This is due in part to the homophily expressed by similarities in the subgroup members. Community members also stated closeness to the MET; one respondent spoke of her personal involvement in monitoring of the park: "if I see something, like other cars around and something not nice, I report it (C9)." However, in contrast, C11 expressed that those individuals who are also family members and working within the MET do not discuss how to solve problems relevant to the role of the MET. In other words, closeness between two actors in a network does not always equate to improved information sharing, problem resolution, and better institutional relationships.

Sources of dissatisfaction include the lack of knowledge sharing, poor protection of critical livelihood elements (e.g. livestock predation by wildlife), and inadequate response when needs arise. For the MET, community members mentioned that the remoteness of the MET office from the Kuiseb was related to less knowledge about how they might support their communities. Concurrently, individuals without livestock had less connection to or reason to engage with MAWF. GBB was perceived to have 'changed' over time in their approaches towards the community - sharing information and transmitting results from their research - pointing to how the current state of GBB is "less visible" than before. Five people made similar statements about the lack of knowledge about what GBB does for the community, and one other individual expressed some nuance to this perception, stating that GBB only shares knowledge with the TTA.

Topnaar community members recommend that all the institutional actors engage and interact with them more frequently, provide more opportunities for development, and advocate to improve the well-being of community 
members (Table 4). The primary advocate for Topnaar people is the Traditional Authority (TTA). While the role of the TTA is to serve as a liaison between local communities and regional and national institutions, the late chief (who passed away in 2019, after we had completed the field work) does not always express good communication with community members. As a result, community members expressed feelings of being encumbered by bureaucracy and inaction of the TTA. Despite the high levels of connectivity and the expectations for the TTA, community members often need to find alternative routes to gaining information and support, and GBB, the MAWF, and the MET potential advocates.

\section{Discussion}

\subsection{Physical Distance and Demographic Factors are not a Factor in Connectivity or Perceptions}

Demographic elements such as physical distance, age, and level of education were not found to be associated with connectivity or perceptions. We expected that older and educated individuals would have higher levels of connection with GBB because most GBB staff are also in this age class and are themselves educated; yet, only education was correlated with higher levels of connection to GBB. This minimal effect, however, suggests that access to social connections with institutions may not be limited by factors such as age or education. Institutions like GBB may therefore benefit from seeking partnerships with individuals from a broad range of communities, rather than individuals of specific age or education classes, in order to increase the heterogeneity and reach of their network There was no correlation between the perceptions and connectivity of community members living close to GBB and the other institutions versus those living further away. The null effect of physical distance and other demographic factors may be attributable to cultural factors such as kinship and cohesion within Topnaar society and how these factors shape connection and perception.

\subsection{Quality Connections Support Better Perceptions of Institutions}

It has been demonstrated that local institutions are important to CBNRM (Nemarundwe 2003), and that social network connectivity contributes to CBNRM outcomes (Crona and Bodin 2006). Through this case, we have demonstrated how quality connections support better perceptions of institutions in the NNNP. In the cases of GBB and the MAWF, our findings are consistent with other studies (Hansen 1999; Reagans \& McEvily 2003); individuals who have better quality connections hold better perceptions of institutions (Table 3).

Along with the TTA, GBB and MAWF are institutions with key boundary actors in the network (Figure 2). In turn, qualitative findings demonstrate that individuals value connections made through employment (GBB), arenas of exchange such as trainings and workshops (GBB and MAWF), and direct livelihood support (GBB and MAWF). High betweenness centrality of MAWF and GBB personnel that operate in this region suggests that they effectively serve as a bridge between the institution and the Topnaar community (Table 2), but the scope of this study did not permit us to explore these dynamics in depth. GBB has three actors who have high levels of betweenness centrality, suggesting that it has greater capacity to support cross-institution CBNRM engagement and collective action. Yet, community members are able to more easily access information and support from MAWF due to the fact that the MAWF representative is Topnaar and lives amongst community members and facilitating these connections.

We do not find a relationship between connections and perceptions in the case of the MET. Qualitative results demonstrate a high level of community dissatisfaction with the MET in regard to human-wildlife conflict and park regulations (Table 4). The MET's purpose is to maintain the park and conserve biodiversity; community members are motivated by livelihood needs that can conflict with the park goals. This dissatisfaction may be the result of these disparate goals; Ostrom (2011) argues that mutual goals are needed for successful intergroup collaboration.

\subsection{More Connections are Often, but not Always, Associated with Greater Engagement with Institutions}

High levels of connectivity and positive perceptions were associated in some, but not all, cases with a willingness to engage with an institution. While high connectivity increases willingness to reach out to an institution in the cases of GBB and the MAWF, positive perceptions only increase willingness to reach out to an institution in the case of the GBB. This is relevant also to the subgroup division demonstrated in the social network (Figure 2), which shows that the upper-level staff at GBB (management and research teams) and the Topnaar communities form two distinct, densely connected subgroups, the latter for which the MAWF representative is included. These distinctions show the limitations in the cohesiveness of the broader community-institution network, as Topnaar staff members at GBB may not possess sufficient power to support or help community members as do the management of GBB.

GBB's Topnaar staff play a key role in connecting GBB to the Topnaar communities. Nevertheless, qualitative data suggests that the existence of these ties did not increase the community's understanding of GBB or help to create an avenue for information sharing about conservation or ecological research. Thus, many of the community- 
GBB ties are not exchanging information in a manner sufficient to support local governance of natural resources. This could be due to other factors not elaborated in this case study such as positionality or perceptions of power and influence, and this finding calls for further study. Another factor inhibiting engagement with GBB is that its main mission is scientific research. Despite its physical position within the Park and among the Topnaar communities, GBB does not have the specific capacity or mission to support community development and reduction of human wildlife conflict. Also, despite these barriers to engagement, perceptions of GBB remain relatively high because GBB is perceived as providing more types of support than the other institutional actors (Table 4).

Similarly, while the TTA serves as the natural boundary actor between the community and other institutions, rural Topnaar residents complain that information rarely filters to the local scale from the TTA (Botelle and Kowalski 1995; Legal Assistance Center 2013). Information exchange provides an avenue for building relationships and can increase the potential for successful collaboration (Ostrom 2011) but may be lacking in the connections present in the Namib-Naukluft institution-community network. Without ties that stimulate information-sharing, connections may not necessarily stimulate the intergroup collaboration needed to support CBNRM. Our findings underscore the idea that improving connectivity and perceptions is necessary to the engagement between institutions and communities, and key to network resilience and the effective management of systems (Ostrom 2011). Such relationships increase levels of trust, facilitate information flow, prioritize the co-production of knowledge, and strengthen benefit-sharing (Berkes 2017).

\section{4 Limitations}

There are several limitations in our study. While qualitative results demonstrate that community members see the MET as spatially distant, we were unable to speak with MET employees during the study to broaden these qualitative perspectives. Therefore, the analysis of how these actors serve within the social network is limited to community perspectives. Furthermore, these results do not account for the ways in which the divergent institutional objectives influence a community member's connectivity to and perception of that institution. Finally, one's personal capacity and the infrastructure available in the NNNP (e.g. cellular network access) influence one's ability to reach out to institutions and are factors that were not considered in this study. Results from this study are most relevant to other rural cases of similar demographic and institutional characteristics but are not generalizable to the wider population.

\section{Conclusion}

This research examined a case study of the indigenous Topnaar community living within the Namib-Naukluft National Park and the institutions concurrently involved in the Topnaar livelihoods in the Park - an ecological research station established in 1962 as a neighbor to the Topnaar communities called Gobabeb Namib Research Institute (GBB), the Ministry of Agriculture, Water, and Forestry (MAWF) that supports livestock and gardening for the Topnaar, and the Ministry of Environment and Tourism (MET) that establishes and supports the enactment of conservation goals in the national park. Drawing on social network analysis and social psychology, we examined the ways in which community members' connectivity relate to perceptions of institutions operating in the Park. We found that higher quality connections between Topnaar community members and the various institutions equates to more positive perceptions of those institution. Connectivity in one case increased one's willingness to reach out to an institution, but perceptions have less of an effect. Finally, we found that physical distance, age and education of actors did not significantly influence connectivity.

While high quality connections relate to positive perceptions and a willingness to reach out to institutions for help, more research is needed to better understand how bridging and boundary actors in this social network and the creation of ties that share not only benefits, but also information and knowledge about CBNRM, can serve to enhance institution-community connectivity and co-management. The education and training stemming from GBB's interactions and the development initiatives stemming from the TTA's leadership (Table 4) support the potential of rural livelihoods, which are constrained by the rules and regulations of the national park. Additionally, we only explored community members' willingness to reach out to institutions for help, but not other forms of collective action, such as participation in community-based research or participation in rulemaking. Greater direct and indirect social connections are key to improved relationships and perceptions between communities and institutions involved in CBNRM.

The main institutions in NNNP face a number of challenges that may limit their ability to satisfy the concerns raised by Topnaar community members. While it is not within the scope of this paper to elaborate on the breadth of these challenges, we explain this through isolated examples. As an ecological research institute, GBB must contend with limited financial resources, the need to satisfy the requirements of funding organizations that 
prioritize ecological research without consideration of local human populations, and a lack of staff members who are trained and available to liaise with Topnaar community members. Likewise, the MET serves a relatively large area and the Kuiseb is just one of several areas where they are expected to meet the concerns of local communities. Our results call attention to the fact that direct connections are essential to improving local community perceptions towards institutions, and thus we recommend several steps that could be taken through policies or specific CBNRM initiatives: 1) increased decentralization of institutions with greater responsibility transferred to local field offices, 2) employment of local community members whenever possible by institutions, especially for the purpose of carrying out community-based programs, 3 ) a greater frequency of face-to-face interactions between communities and institutions via workshops, presentations, or focus group discussions that demonstrate engagement.

\section{Acknowledgments}

This research was supported by a gift from the Paulson Family to the Environmental Studies Program at Dartmouth College. We also are indebted to Prof. Douglas E. Bolger and Michael E. Cox for their contributions to the research design and helpful comments on the manuscript. Finally, we wish to thank Rironderuapi Kavari of the Namibian University of Science and Technology (NUST), the management and staff of the Gobabeb Namib Research Institute and the members of the Topnaar Traditional Authority for their assistance and support of this research.

\section{References}

Berkes, F. (2017). Environmental governance for the Anthropocene? Social-ecological systems, resilience, and collaborative learning. Sustainability, 9(7), 1232. https://doi.org/10.3390/su9071232

Berman, R., Quinn, C., \& J. Paavola. (2012). The role of institutions in the transformation of coping capacity to sustainable adaptive capacity. Environmental Development, 2, 86-100. https://doi.org/10.1016/j.envdev.2012.03.017

Bigdon, C. (2006). Good governance and conflict transformation in Sri Lanka: A political analysis of people's perceptions of institutions at the local level and the challenges of decentralized governance. (Doctoral Dissertation, University of Bonn, Germany).

Bodin, Ö., \& Crona, B. I. (2009). The role of social networks in natural resource governance: What relational patterns make a difference? Global environmental change, 19(3), 366-374. https://doi.org/10.1016/j.gloenvcha.2009.05.002

Botelle, A., \& K. Kowalski. (1995). Changing resource use in Namibia's lower Kuiseb river valley: Perceptions from the Topnaar community. (Master's thesis, Institute of Southern African Studies, University of Lesotho).

Chaffin, B. C., Gosnell, H., \& Cosens, B. A. (2014). A decade of adaptive governance scholarship: synthesis and future directions. Ecology and Society, 19(3). https://doi.org/10.5751/ES-06824-190356

Cooley, C. H. (1998). On self and social organization. University of Chicago Press.

Cox, M., Arnold, G., \& Villamayor Tomás, S. (2010). A review of design principles for community-based natural resource management. Ecology and Society, 15(4), 38. https://doi.org/10.5751/ES-03704-150438

Crona, B., \& Bodin, Ö. (2006). What you know is who you know? Communication patterns among resource users as a prerequisite for co-management. Ecology and society, 11(2). https://doi.org/10.5751/ES-01793-110207

Dietz, T., Ostrom, E., \& Stern, P. C. (2003). The struggle to govern the commons. Science, 302, 1907. https://doi.org/10.1126/science.1091015

Erickson, B. H. (1988). The relational basis of attitudes. Social structures: A network approach, 99(121), 443-475.

Fabricius, C., Folke, C., Cundill, G., \& L. Schultz. (2007). Powerless Spectators, Coping Actors, and Adaptive Comanagers: A Synthesis of the Role of Communities in Ecosystem Management. Ecology and Society, 12(1), 29. https://doi.org/10.5751/ES-02072-120129

Festinger, L., Schachter, S., \& Back, K. (1950). Social pressures in informal groups; a study of human factors in housing. Washington: Harper. https://doi.org/10.2307/3707362

Freeman, L. C. (1977). A set of measures of centrality based upon betweenness. Sociometry, 40, 35-41. https://doi.org/10.2307/3033543

Gargallo, E. (2020). Community conservation and land use in Namibia: Visions, expectations and realities. Journal of Southern African Studies,46(1), 129-147. https://doi.org/10.1080/03057070.2020.1705617

Granovetter, M. (1973). The strength of weak ties. American Journal of Sociology, 76, 1360-1380. https://doi.org/10.1086/225469 
Gupta, J., Termeer, C., Klostermann, J., Meijerink, S., van den Brink, M., Jong, P., ... Bergsma, E. (2010). The adaptive capacity wheel: a method to assess the inherent characteristics of institutions to enable the adaptive capacity of society. Environmental Science \& Policy, 13(6), 459-471. https://doi.org/10.1016/j.envsci.2010.05.006

Hansen, M. T. (1999). The search-transfer problem: the role of weak ties in sharing knowledge across organization subunits. Administrative Science Quarterly, 44, 82-111. https://doi.org/10.2307/2667032

Homans, G. C. (1950). The Human Group. New York: Harcourt, Brace.

Kadushin, C. (1966). The friends and supporters of psychotherapy: on social circles in urban life. American Sociological Review, 786-802. https://doi.org/10.2307/2091658

Knoke, D., \& Yang, S. (2008). Social Network Analysis: Quantitative Applications in the Social Sciences (2nd ed.). Sage Publications. London. https://doi.org/10.4135/9781412985864

Lauber, T. B., Decker, D. J., \& Knuth, B. A. (2008). Social Networks and Community-Based Natural Resource Management. Environmental Management, 42, 677-687. https://doi.org/10.1007/s00267-008-9181-8

Lebel, L., Anderies, J. M., Cambell, B., Folke, C., Hatfield-Dodds, S., Hughes, T. P., \& Wilson, J. (2006). Governance and the capacity to manage resilience in regional social-ecological systems. Ecology and Society, 11(1), 19. https://doi.org/10.5751/ES-01606-110119

Legal Assistance Center. (2013). Indigenous Peoples and Climate Change in Africa: Report on Case Studies of Namibia's Topnaar and Hai||om Communities. Land, Environment, and Development Project.

McPherson, M., Smith-Lovin, L., \& Cook, J. M. (2001). Birds of a feather: homophily in social networks. Annual Review of Sociology, 27, 415-444. https://doi.org/10.1146/annurev.soc.27.1.415

Mosimane, A. W., \& Silva, J. A. (2015). Local governance institutions, CBNRM, and benefit-sharing systems in Namibian conservancies. Journal of Sustainable Development, 8(2), 99-112. https://doi.org/10.5539/jsd.v8n2p99

Nemarundwe, N. (2003). Negotiating Resource Access: Institutional arrangements for woodlands and water use in southern Zimbabwe. (Doctoral dissertation, Uppsala University, Sweden).

Olsson, P., \& Folke, C. (2004). Adaptive Co-management for Building Resilience in Social-Ecological Systems. Environmental Management, 34(1), 75-90. https://doi.org/10.1007/s00267-003-0101-7

Olsson, P., Gunderson, L. H., Carpenter, S. R., Ryan, P., Lebel, L., Folke, C., \& Holling, C. S. (2006). Shooting the rapids: navigating transitions to adaptive governance of social-ecological systems. Ecology and Society, 11(1), 18. https://doi.org/10.5751/ES-01595-110118

Ostrom, E. (1990). Governing the Commons: The Evolution of Institutions for Collective Action. New York: Cambridge University Press. https://doi.org/10.1017/CBO9780511807763

Ostrom, E. (2007). A diagnostic approach for going beyond panaceas. PNAS, 104(39), 15181-15187. https://doi.org/10.1073/pnas.0702288104

Ostrom, E. (2011). Background on the institutional analysis and development framework. Policy Studies Journal, 39(1), 7-27. https://doi.org/10.1111/j.1541-0072.2010.00394.x

Pahl-Wostl, C. (2009). A conceptual framework for analyzing adaptive capacity and multi-level learning processes in resource governance regimes. Global Environmental Change, 19, 354-365. https://doi.org/10.1016/j.gloenvcha.2009.06.001

Reagans, R., \& McEvily, B. (2003). Network structure and knowledge transfer: the effects of cohesion and range. Administrative Science Quarterly, 48, 240-267. https://doi.org/10.2307/3556658

Sanginga, P. C., Kamugisha, R. N., \& Martin, A. M. (2010). Strengthening Social Capital for Adaptive Governance of Natural Resources: A Participatory Learning and Action Research for Bylaws Reforms in Uganda. Society \& Natural Resources: An International Journal, 23(8), 695-710. https://doi.org/10.1080/08941920802653513

Sjöstedt, M. (2015). Resilience revisited: taking institutional theory seriously. Ecology and Society, 20(4), 23. https://doi.org/10.5751/ES-08034-200423

Vincent, K. (2007). Uncertainty in Adaptive Capacity and the Importance of Scale. Global Environmental Change, 17(1), 12-24. https://doi.org/10.1016/j.gloenvcha.2006.11.009 
Wasserman, S., \& Faust, K. (1994). Social network analysis: Methods and applications. New York: Cambridge University Press. https://doi.org/10.1017/CBO9780511815478

Wey, T., Blumstein, D.T., Shen, W., \& Jordán, F. (2008). Social network analysis of animal behavior: a promising tool for the study of sociality. Animal Behavior, 75, 333-344. https://doi.org/10.1016/j.anbehav.2007.06.020

\section{Note}

Note 1. As the article was going being published, the names of the two ministries changed to the Ministry of Environment, Forestry, and Tourism and the Ministry of Agriculture, Water, and Land Reform.

Appendix 1. Connectivity Quality Score. To assess the strength of each connection, connectivity quality score ranges from zero to five - zero indicating weak connectivity and five indicating strong connectivity.

\begin{tabular}{lll}
\hline Score & Indicator & Description \\
\hline 0 & Nonexistent & Doesn't interact with anyone from the institution \\
\hline 1 & Very Weak & Doesn't interact with individuals from the institution often \\
\hline 3 & Weak & $\begin{array}{l}\text { Interacts with individuals from the institution sometimes, but doesn't talk about } \\
\text { the institution at all }\end{array}$ \\
\hline 4 & Okay & $\begin{array}{l}\text { Interacts with individual often, but only talks about the institution rarely and } \\
\text { doesn't learn about the institution's greater work through the relationship }\end{array}$ \\
\hline 5 & Strong & Interacts with individuals from the institution to talk about the institution's work \\
\hline
\end{tabular}

Appendix 2. Perception Score (P) Assessment. The five-point perception score uses the ratio of positive to negative opinions expressed during the interview to assess respondents' perceptions of an institution.

\begin{tabular}{lll}
\hline Perception Score & Indicator & Description of perceptions of institution \\
\hline 0 & Nonexistent & Complete lack of knowledge \\
1 & Very Bad & Strong negative opinions \\
2 & Bad & Primarily negative opinions \\
3 & Okay & Balance of positive and negative opinions \\
4 & Good & Primarily positive opinions \\
5 & Very Good & No critique, names positive examples and perceived benefits \\
\hline
\end{tabular}


Appendix 3. Relationship between Connectivity and Demographic factors

\begin{tabular}{|c|c|c|c|}
\hline & (1) & (2) & (3) \\
\hline VARIABLES & MET & GBB & MAWF \\
\hline \multirow[t]{2}{*}{ Age } & -0.0194 & -0.00215 & -0.00202 \\
\hline & $(0.0423)$ & $(0.0369)$ & $(0.0349)$ \\
\hline \multirow[t]{2}{*}{ Years of Education } & -0.00206 & $0.288^{* *}$ & 0.227 \\
\hline & $(0.171)$ & $(0.134)$ & $(0.166)$ \\
\hline \multirow[t]{2}{*}{ Maleness } & -0.161 & -0.591 & -0.156 \\
\hline & $(0.939)$ & $(0.820)$ & $(0.826)$ \\
\hline \multirow[t]{2}{*}{$\ln$ (Distance) } & 0.641 & -0.226 & 0.0377 \\
\hline & $(0.763)$ & $(0.367)$ & $(0.467)$ \\
\hline \multirow[t]{2}{*}{ Constant } & 0.901 & 1.410 & 0.958 \\
\hline & $(3.292)$ & $(2.324)$ & $(2.463)$ \\
\hline Observations & 20 & 19 & 17 \\
\hline R-squared & 0.065 & 0.350 & 0.197 \\
\hline \multicolumn{4}{|c|}{ Standard errors in parentheses } \\
\hline \multicolumn{4}{|c|}{$* * * \mathrm{p}<0.01,{ }^{* *} \mathrm{p}<0.05, * \mathrm{p}<0.1$} \\
\hline
\end{tabular}

Above results are based on OLS multivariate regression of individual's connectivity quality score on various demographic variables. $\mathrm{Ln}$ (Distance) refers to the natural log of distance. Male is a binary variable where nonmales are zero. Age and years of education are continuous variables.

Appendix 4. Regressions of Community Members' Perceptions of Institutions on Connectivity Quality

\begin{tabular}{lccc}
\hline \multirow{2}{*}{ VARIABLES } & $(1)$ & $(2)$ & $(3)$ \\
& MET & GOB & MAWF \\
Connectivity Quality & -0.157 & $1.032^{* * *}$ & $0.528^{* * *}$ \\
& $(0.244)$ & $(0.138)$ & $(0.165)$ \\
Age & -0.00805 & 0.0234 & -0.00232 \\
& $(0.0411)$ & $(0.0185)$ & $(0.0215)$ \\
Years of Education & 0.124 & -0.0838 & -0.0925 \\
& $(0.154)$ & $(0.0745)$ & $(0.0809)$ \\
Constant & 2.021 & -0.0890 & $2.689^{*}$ \\
& $(2.829)$ & $(1.212)$ & $(1.440)$ \\
& & & \\
Observations & 19 & 19 & 20 \\
R-squared & 0.097 & 0.809 & 0.400 \\
\hline
\end{tabular}

Standard errors in parentheses

$* * * \mathrm{p}<0.01, * * \mathrm{p}<0.05, * \mathrm{p}<0.1$

All models evaluate the relationship between connectivity quality score and perception score using OLS multivariate linear regression. 
Appendix 5. Perceptions and connections related to one's willingness to reach out

\begin{tabular}{|c|c|c|c|c|c|c|c|c|c|}
\hline & (1) & (2) & (3) & (4) & (5) & (6) & (7) & (8) & (9) \\
\hline & MET & MET & MET & GOB & GOB & GOB & MAWF & MAWF & MAWF \\
\hline VARIABLES & Connectivity & Perception & Interaction & Connectivity & Perception & Interaction & Connectivity & Perception & Interaction \\
\hline Perception & & 0.287 & 1.686 & & $1.076^{*}$ & 0.206 & & 0.636 & 0.619 \\
\hline Score & & $(0.470)$ & $(1.290)$ & & $(0.562)$ & (1.369) & & $(0.543)$ & $(1.257)$ \\
\hline Connectivity & 0.183 & & 1.249 & $1.149^{*}$ & & -0.511 & 1.054 & & 3.744 \\
\hline Quality Score & $(0.364)$ & & $(0.934)$ & $(0.665)$ & & $(1.890)$ & $(0.683)$ & & $(3.351)$ \\
\hline Perception * & & & -0.370 & & & 0.255 & & & -0.590 \\
\hline Connectivity & & & $(0.387)$ & & & $(0.298)$ & & & $(0.672)$ \\
\hline Age & 0.00347 & -0.0181 & -0.0156 & 0.0260 & -0.0383 & -0.00798 & 0.0440 & 0.0233 & 0.0409 \\
\hline & $(0.0654)$ & $(0.0678)$ & $(0.0838)$ & $(0.0721)$ & $(0.0657)$ & $(0.0788)$ & $(0.0690)$ & $(0.0643)$ & $(0.0869)$ \\
\hline Years of & $0.585^{*}$ & 0.587 & 1.125 & -0.0704 & -0.0668 & -0.0600 & -0.110 & 0.0511 & -0.255 \\
\hline Education & $(0.347)$ & $(0.394)$ & $(0.690)$ & $(0.347)$ & $(0.367)$ & $(0.315)$ & $(0.261)$ & $(0.234)$ & $(0.359)$ \\
\hline Constant & -5.079 & -4.446 & -13.91 & -3.867 & -1.081 & -1.176 & -2.240 & -2.260 & -4.086 \\
\hline & (4.935) & $(4.903)$ & (9.413) & $(4.506)$ & $(3.927)$ & $(4.831)$ & $(4.371)$ & (4.158) & $(5.490)$ \\
\hline Observations & 18 & 17 & 17 & 15 & 16 & 15 & 16 & 16 & 16 \\
\hline \multicolumn{10}{|c|}{ Standard errors in parentheses } \\
\hline \multicolumn{10}{|c|}{$* * * \mathrm{p}<0.01, * * \mathrm{p}<0.05, * \mathrm{p}<0.1$} \\
\hline
\end{tabular}

All models evaluate the relationship between agency, operationalized as one's willingness to reach out to an institution, and both one's connectivity quality score and one's perception score. Models are estimated using logistic regression given that willingness to reach out is a binary outcome variable. Above logit coefficients can be interpreted as changes in the odds of a community member being willing to reach out associated with one-unit increases in any independent variable used. Coefficients greater than 1 represent an increase in odds while coefficient less than 1 represent a decrease in odds.

\section{Copyrights}

Copyright for this article is retained by the author(s), with first publication rights granted to the journal.

This is an open-access article distributed under the terms and conditions of the Creative Commons Attribution license (http://creativecommons.org/licenses/by/4.0/). 